\#054 Tratamento endodôntico em pré-molar com 3 canais e sistema canalar em C: caso clínico CrossMark

Maria Moreira, Joana Alexandra Marques Simões, Diana Sequeira*, Patrícia Diogo, João Miguel Santos, Paulo Palma

Área da Medicina Dentária Faculdade de Medicina da Universidade de Coimbra

Introdução: Um sistema canalar em C caracteriza-se pela existência de canais radiculares cuja secção transversal tem a forma de "C". Canais em C resultam de falhas na fusão da bainha epitelial de Hertwig, quer do lado lingual quer do vestibular. São mais comuns em segundos molares mandibulares, mas encontram-se descritos também em primeiros e terceiros molares bem como pre-molares mandibulares. Apesar deste tipo de sistema apresentar maior prevalência na população asiática (cerca de 40\%), o clínico deve estar atento para a possibilidade da sua existência e, desse modo, adaptar o seu protocolo. Descrição do caso clínico: Paciente R.P., 56 anos, do sexo masculino, dirigiu-se à consulta com queixas de dor no espaço interproximal, entre o 44 e o 45. À observação oral, verificou-se cárie extensa em mesial do dente 45. Após a realização dos testes de sensibilidade e exames radiográficos (radiografias periapicais e CBCT), verificou-se envolvimento pulpar e diagnosticou-se necrose pulpar sem periodontite apical. Foi realizada remoção de cárie, restauração pré-endodôntica, desbridamento inicial com limas K, instrumentação mecanizada com sistema Protaper Next e obturação com Gutta Flow bioseal e cones de Guta Percha. Follow-up de 6 meses. Discussão e conclusões: O principal objetivo de um tratamento endodôntico é a realização do total desbridamento canalar e a correta remoção de microorganismos e tecido necrótico do canal. É por isso fundamental realizar uma correta avaliação anatómica para o planeamento e sucesso do mesmo. O reconhecimento de sinais clínicos e radiográficos, são fundamentais para avaliar o grau de dificuldade e risco. A execução de CBCT permite confirmar a suspeição de uma variação anatómica, permitindo uma observação mais precisa e dinâmica do dente. Identificou-se um sistema canalar em C, categoria V, segundo a classificação de FAN. A principal dificuldade neste tipo de anatomia é conseguir realizar uma eficaz desinfeção nas zonas de istmo devido à irregularidade dos canais, ocorrendo frequentemente falha do tratamento endodôntico. A utilização de maximização associada a instrumentação mecanizada podem melhorar o prognóstico neste tipo de casos.

http://doi.org/10.24873/j.rpemd.2019.12.517

\section{\#055 Cirurgia apical conservadora: Relato de caso clínico}

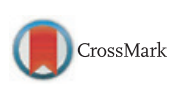

Telma Ferreira*, S Gavinha, P Manarte-Monteiro, Dúnia Mendes, Miguel Albuquerque Matos

Competências Clínicas em Medicina Dentária - Universidade Fernando Pessoa

Introdução: A cirurgia apical está indicada em determinadas condições, em que o retratamento endodôntico não é possível, ou por si só não é a solução. Descrição do caso clínico: Paciente do género feminino, 54 anos, saudável, refere dor no dente 1.2 "ao trincar/bater no dente". No exame clínico, após o teste à percussão vertical e horizontal, verificou-se presença de resposta dolorosa. No exame radiográfico observa-se uma lesão periapical no dente 1.2 previamente endodonciado, reabilitado com coroa cerâmica e espigão intra-radicular, com boa adaptação e estética. Realizaram-se desgastes de prematuridades nos dentes 2.7 e 1.2 e posteriormente, um acréscimo de compósito no dente 1.3 por palatino devido à ausência de contacto em movimentos de lateralidade. Pelo facto do retratamento convencional não cirúrgico implicar a perda da reabilitação protética e pelo risco inerente à remoção do espigão intra-radicular, optou-se pela realização da cirurgia apical. Na consulta de reavaliação, 7 dias após a realização da cirurgia a paciente relatou inexistência de sintomatologia. No follow-up radiográfico, podemos observar alguns sinais de regressão da lesão. Discussão e conclusões: A cirurgia apical está indicada, nos casos em que o retratamento endodôntico não cirúrgico não é possível ou favorável. Neste caso clínico, optou-se pela realização da cirugia apical do dente 1.2 com patologia periapical associada. Foi realizada a apicectomia, retro-preparação e retro-obturação com um material biocompatível para promover o selamento apical. Tendo em consideração uma perspectiva conservadora e o custo-benefício inerente às diferentes opções de tratamento, optou-se pela realização deste procedimento devido à presença de reabilitação protética bem adaptada e espigão intra-radicular. Por este motivo outra opção clínica, como a execução do retratamento convencional não cirúrgico, aportaria muito mais riscos. Considerando as consultas de reavaliação realizadas após 7 dias, um mês e dois meses da realização da cirurgia apical, em que se realizaram follow-ups radiográficos, revelando-se satisfatórios, pode-se concluir que se obteve sucesso com a realização desta opção clínica.

http://doi.org/10.24873/j.rpemd.2019.12.518

\section{\#056 Pênfigo Vulgar - Do diagnóstico à terapêutica (1) CrossMark}

Marcelo Prates*, Ana Teresa Tavares, Luís Sanches Fonseca, Yashad Mussá, Luísa Figueiredo, André Pereira

Centro Hospitalar Universitário de Lisboa Central - Hospital São José

Introdução: O Pênfigo Vulgar é uma doença vesiculobolhosa autoimune crónica rara que se caracteriza pela formação de vesiculas intraepiteliais ou bolhas na pele ou mucosas. Corticóides sistémicos são o tratamento de primeira linha no entanto pode ser necessária a introdução de outros imunossupressores. Descrição do caso clínico: Homem, 49 anos, natural da Índia, vai ao Serviço de Urgência por surgimento de 'bolhas brancas na boca' (sic) há 2 semanas e dor intensa com edema da hemiface direita há 2 dias. Referia sensação de febre e dor à deglutição. Apresentava lesões bolhosas e erosivas de cor vermelha na mucosa jugal bilateralmente, fundo do vestíbulo do $4^{\circ}$ quadrante e região posterior da língua. Lesões cobertas por pseudomembrana de cor nacarada. Com febre de $38,1 .^{\circ} \mathrm{C}$. 
Por suspeita de infeção bacteriana das lesões com sobreinfeção fúngica iniciou-se Amoxicilina Ácido Clavulânico, Fluconazol e analgesia. Pediu-se hemograma e serologias virais e recomendou-se evicção de alimentos picantes. Após uma semana havia melhoria da tumefação da face e da dor mas mantinha lesões erosivas nas mucosas jugais, fundo do vestíbulo e pavimento oral. Análises sem alterações. Optou-se por biopsar lesões. Antes do resultado anatomopatológico, teve nova agudização com dor acentuada e agravamento das lesões erosivas, nesta altura sem pseudomembranas. Excluído quadro infecioso, iniciou-se corticoterapia tópica com betametasona e sistémica com prednisolona. O resultado anatomopatológico e imunohistoquímico revelou tratar-se de Pênfigo Vulgar. Pediu-se TC de corpo que excluiu síndrome paraneoplásica e encaminhou-se a consulta de Doenças Autoimunes para ajustar corticoterapia e iniciar imunossupressores. Após terapêutica numa primeira fase com deflazacorte $90 \mathrm{mg} /$ dia, azatioprina $50 \mathrm{mg} /$ dia e ciclosporina $300 \mathrm{mg} /$ dia, obteve-se estabilização das queixas intraorais com deflazacorte $30 \mathrm{mg} /$ dia e azatioprina $100 \mathrm{mg} /$ dia. Discussão e conclusões: Sendo uma doença potencialmente fatal (mortalidade de 5 a 15\% se não tratada), o correto diagnóstico e a instituição de uma terapêutica eficaz são fundamentais na redução da morbilidade e no prognóstico. O conhecimento da sua apresentação e uma biópsia das lesões com recurso a exames imunohistoquímicos são fundamentais para o diagnóstico. Por ter um tratamento difícil de ajustar e com riscos importantes devido à imunossupressão e efeitos adversos, estes doentes devem ser seguidos num contexto hospitalar em centros com experiência em doenças autoimunes.

http://doi.org/10.24873/j.rpemd.2019.12.519

\section{\#057 Epidermólise Bolhosa Distrófica: Caso Clínico em Estomatologia Pediátrica}

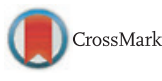

Maria João Morais*, Ana Melissa Marques, Olga Vascan, Beatriz Dominguez, Maria das Dores Lopes, José Pedro Figueiredo

Serviço de Estomatologia - Centro Hospitalar e Universitário de Coimbra, FUMC

Introdução: A Epidermólise Bolhosa Hereditária é uma doença rara, que se manifesta pelo aparecimento de bolhas e lesões espontâneas na pele e na mucosa, em resposta a traumatismos mínimos. Ocorre por mutações genéticas, acometendo as proteínas responsáveis pela coesão entre as diferentes camadas da pele. A Epidermólise Bolhosa divide-se em quatro tipos principais (Simples, Juncional, Distrófica e Síndrome de Kindler), que se distinguem pelas características histológicas, hereditariedade de transmissão - autossómica dominante ou recessiva -, distribuição anatómica das lesões e o nível de clivagem dermo-epidérmica. O diagnóstico é feito através da história clínica, com recurso a biópsia da pele sem bolhas, submetida posteriormente a imunofluorescência direta e/ou microscopia eletrónica. Atualmente, não há um tratamento curativo para a Epidermólise Bolhosa, revelando-se essencial uma abordagem multidisciplinar para proporcionar uma melhor qualidade de vida ao doente. Descrição do caso clínico: Criança do sexo masculino, 8 meses de idade, encaminhada para a consulta de Estomatologia por lesões na cavidade oral em contexto de diagnóstico de Epidermólise Bolhosa do tipo Distrófica autossómica recessiva. A consulta teve como objetivo a avaliação das lesões, orientação do tratamento e prevenção das mesmas, com o propósito de evitar complicações. Foram dados conselhos de higiene oral, dietéticos e reforço da ingestão de água ao longo do dia. Foi prescrita a aplicação de sucralfato na mucosa oral até 3 vezes ao dia, para promoção da cicatrização e da reepitelização da mucosa ulcerada. Discussão e conclusões: A Epidermólise Bolhosa é uma doença complexa com prognóstico grave nos subtipos mais severos. A forma recessiva da Epidermólise Bolhosa distrófica é considerada a mais grave, apresentando lesões orais mais significativas, como microstomia, anquiloglossia, obliteração vestibular e carcinoma de células escamosas. O tratamento incide nos cuidados de suporte, na prevenção e tratamento das lesões a fim de evitar complicações. As medidas de higiene oral, nomeadamente a escovagem diária, o aconselhamento dietético, a administração de flúor e gel de clorohexidina, são fundamentais para evitar o aparecimento de cáries e doença periodontal. http://doi.org/10.24873/j.rpemd.2019.12.520

\section{\#058 Influência do incorreto desenho protético em prótese fixa sobre implantes}

Diogo Soares*, João Manuel Santos Marques, José Mário Rocha, Pedro Fernandes, Francisco Gois, JC Sampaio-Fernandes

\section{FMDUP}

Introdução: O edêntulismo é uma condição irreversível e debilitante descrita como a etapa final de um processo gradual de doença oral. Nesta condição, os pacientes procuram uma solução que não só permita restabelecer eficiência mastigatória e a função fonética, mas também realce a estética facial. A reabilitação fixa sobre implantes é normalmente a solução mais desejada por este tipo de pacientes, devido á comodidade e eficiência mastigatória que lhe está associada, repondo as condições perdidas. Por outro lado, a utilização de próteses removíveis suportadas por implantes, pode em certas situações, permitir melhor estética e maior facilidade na sua higienização. O caso clínico abaixo apresentado, descreve uma reabilitação fixa superior e inferior, que por várias razões, parece não ter sido a melhor opção para esta paciente. Descrição do caso clínico: Paciente totalmente edêntula no maxilar superior e inferior, portadora de prótese fixa superior e inferior realizada por outro profissional há cerca de 10 anos, tendo-se apresentado na consulta do Curso de Especialização em Reabilitação Oral da Faculdade de Medicina Dentária da Universidade do Porto devido ao mau hálito e à dificuldade em higienizar as suas próteses. Verificou-se durante o exame clínico a presença de abas vestibulares em ambas as próteses fixas que comprometiam a correta higienização da mesma. Associado a esta dificuldade, a paciente apresenta dis- 